\title{
La reforma urbana en Brasil y su semántica
}

\begin{abstract}
Rérisson Máximo. Universidade de São Paulo, São Paulo, Brasil. Luciana Royer. Universidade de São Paulo, São Paulo, Brasil.
\end{abstract}

RESUMEN | Con la llegada del siglo XXI, estudiosos de lo urbano celebraron el Estatuto de la Ciudad y el Ministerio de las Ciudades como importantes marcos normativo e institucional de la política urbana en Brasil. Poco tiempo después, las convicciones eran colocadas en jaque ante los impasses que aquellas propuestas enfrentaban. Aún en la primera década del Estatuto y del Ministerio, el campo político e intelectual que orbita en torno de la reforma urbana vivió una etapa de evaluación del proceso. En el momento de su institucionalización, un ciclo más de la reforma urbana se cierra. Pero, ¿qué se acordó llamar reforma urbana? Se argumenta que la respuesta a esa pregunta se podría formular a partir de la explicitación de elementos que definirían una semántica que aquella expresión engloba. Son esos aspectos los que este texto busca presentar y discutir, señalando límites y contradicciones de la reforma urbana como horizonte posible y/o imaginado.

PALABRAS CLAVE | política urbana, política habitacional, planificación urbana.

ABSTRACT | At the turn of the twenty-first century, urban scholars welcomed Brazil's City Statute and the Ministry of Cities as important normative and institutional frameworks for urban policy. A decade later, the convictions were tested by the limits such proposals represented. Years later, after the implementation of the statute and the ministry, the political and intellectual field connected to the urban reform was in an evaluation stage. At the moment of its institutionalization, one more cycle of urban reform closes. However, it is worth questioning: What has become known as urban reform? It is argued that the answer can be constructed from elements that would define a semantics that this expression encompasses. This paper seeks to present and discuss these questions, as well as identify limits and contradictions of urban reform as a possible and(or) imagined horizon.

KEYWORDs | urban policy, housing policy, urban planning. 


\section{Introducción}

En la Conferencia Hábitat III de la Organización de las Naciones Unidas (ONU), realizada en 2016, fue presentada la Nueva Agenda Urbana (NAU), un documento no vinculante para orientar las políticas urbanas mundiales y la acción de gobiernos, de instituciones y de la sociedad en esta temática para las dos próximas décadas. Una de las acciones estratégicas reconocidas en este documento es la adopción de políticas urbanas nacionales y de marcos jurídicos relacionados con el desarrollo urbano, también entendidos como leyes nacionales de desarrollo urbano y ordenamiento territorial (oNU, 2016).

Algunos de los contenidos y características de los marcos jurídicos previstos por la NAU están orientados a superar las carencias y problemas urbanos, con un fuerte compromiso en la defensa de derechos humanos y sociales, condicionamiento de la propiedad de la tierra al cumplimiento de su función social y reconocimiento de la existencia de los pobres en el territorio. Tales características son fruto del movimiento por una reforma urbana que a lo largo del siglo xx fue organizándose en América Latina y ocupando espacio en los gobiernos, en las universidades, en las agencias de cooperación y en las organizaciones no gubernamentales, con una fuerte movilización social, especialmente de los movimientos sociales de lucha por la vivienda y por el derecho a la ciudad.

Uno de los resultados de ese movimiento es la existencia de leyes nacionales de desarrollo urbano y ordenamiento territorial en los países latinoamericanos. A pesar de la distinción y relevancia regional del Estatuto de la Ciudad, principal ley sobre política urbana en Brasil, existen innúmeros otros marcos jurídicos que señalan el derecho a la ciudad y contemplan cuestiones de reforma urbana, como ocurre en Colombia, en México y en Ecuador. Un estudio reciente de la Cities Alliance (2017) identificó once leyes nacionales de desarrollo urbano y ordenamiento territorial en América Latina y el Caribe, con diversidad temporal y de contenido. Sin embargo, a pesar de la importancia de estos marcos jurídicos nacionales en América Latina, que junto con otras acciones constituyen lo que podría llamarse institucionalización de la reforma urbana, es necesario reconocer algunos límites y contradicciones presentes en este proceso. Tomaremos el ejemplo brasileño para profundizar tales cuestiones.

En Brasil, durante los años 2000, diversos estudios y estudiosos de lo urbano celebraron $^{1}$ el Estatuto de la Ciudad y el Ministerio de las Ciudades como importantes marcos normativo e institucional, respectivamente, de la política urbana en Brasil, que se presentan como resultado de un largo proceso que se extiende desde la década de 1960 en la lucha por una reforma urbana (Cardoso \& Ribeiro, 2003; Fernandes, 2008; Maricato, 2011; Rolnik, 2009). El Estatuto y el Ministerio representaban avances en la democratización de la gestión urbana (Rolnik, 2009) y en la estructura legal e institucional, como resultado directo de la lucha popular por la reforma urbana y de su institucionalización. Por ello, ese momento es tratado como un ciclo institucional (Arantes, 2014; Maricato, 2011).

1 Diversos autores, con reparos, postularon un escenario promisorio para las ciudades brasileńas a partir de esos nuevos marcos para la política urbana. Podemos citar los trabajos de Baldez (2003), Bassul (2002), Cardoso y Ribeiro (2003), Fernandes (2002), Maricato (2001) y Rolnik (2006). 
Sin embargo, si la llegada del siglo xxi trajo un escenario que proyectaba un horizonte de avances en lo que se refiere a las condiciones de vida en las ciudades, en la misma década las convicciones y utopías fueron puestas en jaque ante los impasses que representaban aquellas propuestas. Esto se confirma cuando se observa el campo político e intelectual que orbita en torno a la cuestión urbana, vivenciando un periodo de equilibrio con innúmeros eventos y publicaciones que tenían como objetivo realizar análisis, discusiones, críticas y evaluaciones de los efectos producidos por y a partir de los marcos normativo e institucional de la política urbana. ${ }^{2}$ Recientes trabajos se han dedicado a discutir la propia idea o el concepto de 'reforma urbana', sea por medio de análisis coyunturales o por estudios focalizados en aspectos específicos de su gramática. ${ }^{3}$ Lo que se observa es un escenario de crítica con relación al camino que tal conjunto de ideas representó y los límites y contradicciones que se configuran para su efectiva y plena implementación.

No obstante, pese al reconocimiento de avances en el marco regulatorio y en su estructura institucional, aquellos involucrados con la cuestión urbana (todavía) se preguntan sobre las razones que explican por qué las ciudades no están mejores. Es esta la idea de Maricato (2011) sobre el impasse urbano, traducida en la hipótesis de que las banderas de la reforma urbana "alcanzaron su límite", habiendo sido neutralizadas o reducidas en el momento en que se mostraban más promisorias desde el punto de vista político, normativo e institucional. La autora afirma que, en el momento de su institucionalización, se cierra un ciclo (más) de la reforma urbana. Pero ja qué se acordó llamar 'reforma urbana'? Se argumenta que la respuesta a esta pregunta se puede formular a partir de la explicitación de la semántica y la gramática que la expresión engloba.

Considerando esa coyuntura, este texto busca presentar y discutir, a partir de los trabajos que componen tal evaluación reciente de la reforma urbana, cuáles son los elementos que definirían una semántica, ${ }^{4}$ señalando también los límites y contradicciones de la reforma urbana como horizonte posible y/o imaginado. Por tanto y ante el momento de impasse y balance crítico de lo que se acordó en llamar 'reforma urbana', cabe discutir sus significados, en la medida en que la expresión, y los conceptos vinculados a ella, desarrollan diferentes contornos a lo largo del recorrido histórico de la lucha por su implementación.

2 Entre los eventos podemos destacar una mesa en el Encuentro Nacional de la Asociación Nacional de Postgrado e Investigación en Planificación Urbana y Regional, llevada a cabo en Río de Janeiro; el Seminario "Estatuto +10", celebrado en Brasilia, y organizado por el Ministerio de las Ciudades; y además el Seminario Internacional "10 Años del Estatuto de la Ciudad”, que tuvo lugar en Porto Alegre. De las publicaciones, podemos citar los trabajos de Maricato (2011) y Rolnik (2009; 2012).

3 Algunos tienen un carácter más amplio, como ocurre con los trabajos de Burnett (2009), Caldas (2015) y Costa (2012). Otro grupo, como Faria (2012), Santo Amore (2013) y Serafim (2013), se concentra en aspectos particulares sin, no obstante, dejar de relacionar la reforma urbana a una coyuntura más amplia.

4 Adoptamos el término 'semántica' buscando una aproximación a su uso como componente del sentido de las palabras y de la interpretación de las frases. En el caso de la reforma urbana, que se caracteriza por una polisemia, destacamos algunos de los sentidos que la expresión puede presentar, sin construir, no obstante, una definición única. 
Como recurso metodológico, se recurrió a una revisión bibliográfica a partir de publicaciones ya consagradas en la literatura que tratan de la temática (Baldez, 2003; Bassul, 2002; Cardoso \& Ribeiro, 2003; Fernandes, 2008; Maricato, 2011; Rolnik, 2009; Silva, 1991), y de publicaciones recientes que hacen un análisis crítico del tema (Burnett, 2009; Caldas, 2015; Costa, 2012; Faria, 2012; Santo Amore, 2013; Serafim, 2013). Con relación a esos trabajos, el texto presenta formulaciones conceptuales, hipótesis y constataciones sobre la antirreforma urbana (Arantes, 2014); en relación con la merma en la lucha por una utopía mínima (Caldas, 2015), el ocaso de la reforma urbana (Costa, 2012), la fetichización del plan director (Burnett, 2009) y el predominio del discurso del derecho a la ciudad y la permanencia de la ciudad como negación de ese derecho (Faria, 2012); todo eso presente en un momento en el que ocurren importantes avances normativos e institucionales sobre la cuestión urbana.

El texto está dividido en tres partes principales, además de esta introducción. Primero, en la sección “¿Finaliza un ciclo (más) de la reforma urbana en Brasil?”, se presenta un brevísimo panorama histórico de la reforma urbana. En la sección siguiente, "La semántica de la reforma urbana", se define la polisemia del término, visto como ideario, proyecto, movimiento y agenda. Finalmente, se discuten algunos de los límites y contradicciones de la reforma urbana en Brasil.

\section{¿Finaliza un ciclo (más) de la reforma urbana en Brasil?}

La historia de lo que se acordó llamar 'reforma urbana' es contada a partir de momentos que componen una trayectoria lineal y heterogénea, con cambios en la dinámica de los actores, de los procesos y de los resultados alcanzados. En un intento por rescatar la trayectoria que caracteriza aquel concepto polisémico, adquiere relevancia observar las formas como la sociedad civil se movilizó con relación al Estado y cómo este ha respondido a las demandas presentadas, sea a través de políticas urbanas, de acciones directas o en la esfera normativa.

Diversos trabajos ya emprendieron la tarea de reconstruir la trayectoria histórica de la reforma urbana, desde el surgimiento de la expresión y del contenido a ella asociado, en la década de 1960, hasta la actualidad, cuando la política urbana y la lucha por la reforma urbana viven un momento difícil. Burnett (2009), por ejemplo, destaca la existencia de dos momentos importantes, distanciados histórica y temporalmente, que conformarían dos proyectos de reforma urbana y que presentan semejanzas y diferencias, pero con la posible existencia de una línea de continuidad entre ellos. El primero nace al interior de un movimiento mayor, junto a las Reformas de Base; 5 y el segundo está vinculado a la construcción de una

$5 \longdiv { \text { Esta amplia denominación reunía un conjunto de iniciativas que pretendían reformas sectoriales } }$ y que significaban una cierta modificación de los fundamentos en los que estaba estructurada la sociedad brasileńa. El término hace referencia a una nueva plataforma política presentada en 1958 por el partido político del futuro presidente João Goulart. Se trataba de un conjunto de propuestas vinculadas a la intensificación del proceso de industrialización y, principalmente, a la defensa del patrimonio económico y cultural del país; y consistían en las reformas bancarias, fiscal, urbana, administrativa, agraria, universitaria y política (Moreira, 2011). 
plataforma de reivindicaciones de los movimientos populares dirigida a la Asamblea Nacional Constituyente, que retomó aquella denominación y se constituyó en el Movimiento Nacional y posteriormente en el Foro Nacional de la Reforma Urbana.

Santo Amore (2013) hace una división en cinco periodos que aparecen como "ciclos activos" o "latencias". El primero de ellos trata sobre las proposiciones del Seminario de Habitación y Reforma Urbana de 1963; el segundo se refiere al periodo del régimen militar hasta la Asamblea Nacional Constituyente; el tercer ciclo tiene como marcos el inicio de la vigencia de la Constitución en 1988 y los primeros años de la década de 2000, cuando se sancionó el Estatuto de la Ciudad y se eligió presidente a Luiz Inácio Lula da Silva. La creación del Ministerio de las Ciudades y la implementación de una serie de acciones que derivan de dicho cuerpo, definen el cuarto ciclo. Los Programas de Aceleración del Crecimiento y Mi Casa Mi Vida configuran el contexto actual, que conformaría el quinto periodo.

Serafim (2013) divide la historia de la reforma urbana en tres grandes momentos. Primero, la política urbana en el siglo xx, con sus luchas sociales, el reconocimiento por parte del Estado y las primeras conquistas del Movimiento Nacional de la Reforma Urbana (MNRU). Después, destaca la política y la reforma urbana desde la Constitución a la elección de Lula, cuando se amplía el repertorio del Foro Nacional de la Reforma Urbana (FNru) y la lucha dentro del Estado. Finalmente, señala como tercer gran momento la constitución del Ministerio de las Ciudades y todo el camino recorrido por las políticas urbanas a partir de entonces. Costa (2012), por su parte, adopta una periodización construida a partir de la identificación de fases de la constitución del capitalismo y de la forma de expresión asumida por este. Distingue tres fases en horizontes sistémicos distintos, siendo los dos iniciales aquellos de la formación del proyecto de la reforma urbana -el primero, en el horizonte del capitalismo tardío; el segundo, en la transición hacia la mundialización capitalista- y el tercero, que corresponde a la fase de su puesta en marcha, en el horizonte del capitalismo globalizado.

Con relación a ese panorama, cabe destacar el trabajo de Maricato (2011), en el cual se presenta la idea de los ciclos de lucha por la reforma urbana, siendo inclusive referenciado en casi todos los recientes trabajos sobre el tema. Desde la lucha contra la dictadura y por la redemocratización a finales de los años setenta y a lo largo de los años ochenta -que retoma la propuesta de reforma urbana formulada en los años sesenta, durante el gobierno del presidente João Goulart- hasta la elección presidencial de Lula y la creación del Ministerio de las Ciudades, pasando por diversas conquistas legislativas y prácticas en diversos niveles de gobierno y por la pérdida de fuerza de los movimientos reunidos bajo esa bandera, la autora organiza los argumentos para constatar que hubo en ese lapso un deterioro de las condiciones de vida en las ciudades y que ese ciclo se habría cerrado. Presenta la tesis del fin de un ciclo más de la reforma urbana con la creación del Ministerio de las Ciudades, al notar el 


\begin{abstract}
"fin de un ciclo": (...) esto es, fin de un periodo caracterizado por el movimiento social iniciado en la lucha contra la dictadura, que genéricamente podemos denominar de reforma urbana, y que culminó con la creación del Ministerio de las Ciudades en el Gobierno Lula (...). Se acabó un ciclo que prenunciaba reformas urbanas, en especial la reforma de tierras e inmobiliaria. La experiencia de las "alcaldías democráticas y populares” parece haber llegado al límite. La producción académica crítica está en un impasse. Gran parte de los movimientos sociales y sindicales está contenida entre el pragmatismo y el corporativismo. (Maricato, 2011, pp. 8-9, traducción libre)
\end{abstract}

A pesar de los diferentes abordajes, se constata en la literatura analizada acontecimientos específicos que funcionan como marcos o puntos de inflexión. Son ellos el Seminario de Habitación y Reforma Urbana, la Asamblea Nacional Constituyente, el Estatuto de la Ciudad y el Ministerio de las Ciudades. Estos marcos presentan un carácter distinto en los diferentes momentos históricos en que emergen, con enfoques profesional-científico, político-legislativo, normativo e institucional, los cuales dan peso explicativo a la dinámica que la lucha por la reforma urbana presenta, incluso reforzando la polisemia asociada al término.

\title{
La semántica de la reforma urbana
}

Tanto la literatura especializada como las publicaciones dedicadas a la advocacy y a la militancia relacionadas con la reforma urbana, generalmente presentan la expresión acompañada de un complemento que funciona sustantivándola o adjetivándola. Lucha, campo, bandera, movimiento, plataforma, ideario, foro, agenda y proyecto son algunos de los términos que acompañan la idea de reforma urbana como concepto a lo largo de su proceso histórico. En esta parte del texto buscaremos discutir la semántica del término 'reforma urbana'. Para ello, escogimos cuatro aspectos de esa diversidad polisémica para reflexionar sobre las diferentes posibilidades de entendimiento. En esta línea, se realizó la tarea de discutir la polisemia del término como ideario, proyecto, movimiento y agenda. Tales nociones aparecen en los diferentes y diversos trabajos que discuten la temática y que, por lo menos a primera vista, convergen desde diferentes expresiones en una única, lo que a veces genera cierta confusión para su comprensión. Sin embargo, como se discutirá, las ideas en torno a la expresión 'reforma urbana' reciben distintos significados a medida que ese proceso avanza históricamente.

El ideario de la reforma urbana remite al sentido de bandera o utopía defendidos inicialmente en las reformas de base y por burocracias especializadas provenientes de comunidades epistémicas que compartían los mismos ideales, y más tarde por movimientos urbanos. La actuación de estos sectores organizados de la sociedad brasileña en torno al Movimiento Nacional y, posteriormente, del Fórum Nacional de la Reforma Urbana, caracterizan el movimiento de reforma urbana. El proyecto de reforma urbana remite a la plataforma o al conjunto organizado de proposiciones que serán elaboradas en diferentes momentos, confluyendo en instrumentos normativos y legales inspirados en las ideas y acciones desarrolladas por los que 
actúan en ese campo. En lo que se refiere a la agenda de la reforma urbana, esta será discutida como alejada del enfoque propuesto por la literatura consagrada de la ciencia política, visto que la institucionalización de su gramática no representó efectivamente la inserción de las propuestas en la agenda de políticas públicas.

\section{Reforma urbana como ideario}

La noción de reforma urbana como ideario se refiere, directa e inicialmente, al momento en el que se acuña la expresión y comienzan a atribuírsele conceptos que inclusive la acompañan a lo largo de su trayectoria histórica hasta los días actuales. Es posible observar tal aspecto en dos marcos iniciales: en el Seminario del Instituto de Arquitectos de Brasil (IAB), en 1963, inclusive conformando el tema discutido en el evento, y también en torno a las Reformas de Base. Esta sería la expresión mayor del reformismo vinculado a la ideología nacional popular que circundaba el gobierno de João Goulart (1961-1964) y que se transformó en la principal palabra de orden de ese gobierno, constituyendo un marco ideológico con el cual se pretendía ampliar su base de sustentación política (Moreira, 2011).

Entre el conjunto de propuestas que componían las Reformas de Base, la Reforma Agraria era la que mejor representaba el objetivo de asociar un planeamiento nacionalista de industrialización de una política distributiva. Había además una propuesta secundaria, que caracterizaría una Reforma Urbana capaz de "disciplinar el uso y la posesión del suelo urbano y de controlar la ganancia y el abuso de los propietarios de inmuebles y de especuladores de terrenos" (Moreira, 2011, p. 262). La idea inserta en las discusiones institucionales sobre las Reformas de Base apuntaba a la "planeación y reglamentación del crecimiento de las ciudades" y las "desapropiaciones de lotes urbanos" (Moreira, 2011, p. 261) como directrices generales. Había, además, una propuesta de elaboración de un Plan Nacional de Habitación, una de cuyas directrices era coordinar los recursos destinados a la habitación provenientes de diversas fuentes (Moreira, 2011).

El término 'reforma urbana' también aparece en el evento promovido por el IAB, en 1963. Llamado "Seminario de Habitación y Reforma Urbana”, denunció la desigualdad social en las ciudades e identificó el déficit habitacional como cuestión crítica, alertando respecto del aumento de las llamadas "subhabitaciones". Seńaló igualmente el desajuste entre el crecimiento demográfico en las ciudades y el acceso a servicios públicos, como una especie de anticipación del concepto de 'expoliación urbana' surgido más tarde (Kowarick, 2000).

En el seminario se dio una fuerte centralidad de la temática habitacional. El problema habitacional fue observado como derivado de las condiciones de subdesarrollo y de la desproporción entre renta de la población y precios de adquisición o arriendo de vivienda. Como respuesta, se pregonaban "límites al derecho de propiedad y el uso del suelo". Sobresale la idea de función social de la propiedad y del uso del suelo, con las propuestas sugeridas buscando penalizar actividades especulativas. De manera genérica, se examinó también la participación de la sociedad en el desarrollo local, afirmándose que "es de gran importancia para la política habitacional la formación de una conciencia popular del problema y la participación del pueblo en programas de desarrollo de comunidades" (Serafim, 2013). 
Entre las varias conclusiones y propuestas del evento, destaca la creación de un órgano nacional con autonomía financiera, que centralizaría la política habitacional, establecería un Plan Nacional de Habitación y administraría un Fondo Nacional de Habitación. Ello se concretizó posteriormente en el Banco Nacional de Habitación, reforzando las tendencias tecnocráticas y centralizadoras de los recursos federales. La mayor parte de estas proposiciones se enviaron directamente al Ejecutivo federal, en la búsqueda de la aprobación de un proyecto de ley en el Congreso Nacional que incluyera los principios de Política Habitacional y de Reforma Urbana formulados en el seminario (Bassul, 2002).

\section{Reforma urbana como proyecto}

La noción de reforma urbana como proyecto está asociada a la formalización del conjunto de ideas que rodean esta expresión. Esa formalización, sin embargo, a pesar de encontrarse materializada en un documento específico, carga un conjunto de ideas, conceptos y propuestas que se fueron consolidando a medida que el proceso histórico de la reforma urbana se desarrollaba. Destacamos, según ese entendimiento, el Proyecto de Ley de Desarrollo Urbano (pl 775, de 1983), emanado del Poder Ejecutivo, y que inspiró la edición del Proyecto de Ley 181 de 1989, recibiendo en la Cámara de Diputados la clasificación de Proyecto de Ley 5788/90, que más tarde se convertiría en la Ley Federal 10257/2001, más conocida como Estatuto de la Ciudad. Además, están el Proyecto de Enmienda Constitucional de la Reforma Urbana presentado a la Asamblea Nacional Constituyente ${ }^{7}$ y el Proyecto de Ley del Fondo Nacional de Vivienda Popular (pL 2710, de 1992).

El Proyecto de Ley de Desarrollo Urbano (pL 775) de 1983, elaborado por el Consejo Nacional de Desarrollo Urbano, fue una respuesta del Estado a las demandas de organizaciones y articulaciones de la sociedad civil en los años 1970 e inicio de 1980. Fue un intento de creación de un marco regulatorio del desarrollo urbano que se venía gestado en el periodo, y que fue consolidado en un proyecto de ley elaborado por el Ejecutivo (Santo Amore, 2013). Este proyecto:

dispone sobre los objetivos y la promoción del desarrollo urbano y da otras providencias (...) [y] define normas de ocupación del suelo urbano, caracteriza la función social de la propiedad urbana, fija las directrices, instrumentos, equipos urbanos, equipos comunitarios, dicta normas para la regularización de la tierra de áreas urbanas, crea el derecho de preferencia y el derecho de superficie en relación a los terrenos urbanos. (Brasil, 1983)

Según Faria (2012), el proyecto de ley presenta un "nuevo concepto de propiedad urbana", condicionado por el "factor social"; introduce una serie de instrumentos jurídicos que tendrían la función de permitir mayor control sobre la propiedad y coloca la función social estrictamente asociada al desarrollo urbano. Incluso habiendo sido solamente un proyecto, esta referencia ya poseía elementos que determinarían o estarían presentes en la concepción actual de la función social de

7 Después de dos décadas de régimen militar, y con la apertura política a partir de 1985, se instaló una Asamblea Nacional Constituyente en 1987, que culminó en la promulgación de una nueva Constitución Federal en 1988. 
la propiedad urbana presente en el Estatuto de la Ciudad y defendida por el FNRU. De acuerdo con Santo Amore (2013), el proyecto de ley tenía una orientación tecnocrática y una funcionalidad de respuesta institucional e ideológica a demandas populares en tres ejes: participación, regularización de la tierra y control sobre la propiedad.

De las luchas lideradas por los movimientos sociales urbanos en las décadas de 1970 y 1980, una de las mayores conquistas fue la acción asumida por la Constituyente de Enmienda Popular por la Reforma Urbana. Formulado por el MNRU, contó con el apoyo de seis entidades y cerca de 150 mil firmas (Santo Amore, 2013). La enmienda contenía veintitrés artículos, divididos en cinco capítulos que abordaban las siguientes temáticas: derechos urbanos, propiedad inmobiliaria urbana, política habitacional, de transportes y servicios públicos y gestión democrática de la ciudad. Los derechos a la vivienda, al transporte público, al saneamiento y a la gestión democrática de la ciudad, entre otros, se presentaban como obligación del Estado, además de indicar que "el derecho a condiciones de vida urbana digna supedita el ejercicio del derecho de propiedad, al interés social en el uso de los inmuebles urbanos".

Este proyecto de Enmienda Constitucional resultó en la inclusión en la Constitución Federal de los artículos 182 y 183 que tratan de la Política Urbana, además de otras importantes Enmiendas Constitucionales vinculadas a la habitación y al medioambiente. Siendo un marco en la demarcación de principios democráticos, significó un gran avance en el orden jurídico y político, sobre todo en lo que concierne a las bases para la formulación de una nueva política de desarrollo urbano. De hecho, el nuevo texto constitucional incorporó principios generales del MNRU para la política de desarrollo urbano: derecho a la ciudad, función social de la propiedad y gestión democrática. Cabe resaltar que la política urbana como capítulo era inédita en las constituciones anteriores y "representó la apertura de un campo importante para la lucha política a favor del derecho a la ciudad, tema central en la plataforma de la reforma urbana" (Silva, 2002, p. 147).

Pocos ańos después se presentó el Proyecto de Ley del Fondo Nacional de Vivienda Popular (pL 2710, de 1992), el primer proyecto de ley de iniciativa popular impulsado después de la promulgación de la Constitución Federal de 1988. Con su propuesta de creación de un fondo público para subsidiar viviendas populares, tal proyecto fue aprobado solamente en 2005, durante el gobierno Lula. Se transformó en la Ley Federal 11.124, que creó el Sistema Nacional de Habitación de Interés Social (sNHIs), el Fondo Nacional de Habitación de Interés Social (FNHIs) e instituyó el Consejo Gestor del FNHIs. Esta legislación deriva de aquella moción entregada al Congreso Nacional por los MNRU en el inicio de la década de 1990, y tiene como principales objetivos garantizar inversiones y subsidios para habitación direccionados a la población de baja renta, y centralizar todos los programas y proyectos destinados a la habitación de interés social (Serafim, 2013).

La Ley Federal 10.257/2001, llamada Estatuto de la Ciudad, tuvo su origen en el Proyecto de Ley 775 de 1983, oriundo del propio Poder Ejecutivo, que inspiró la edición del Proyecto de Ley 181/89, recibiendo en la Cámara de Diputados la clasificación de Proyecto de Ley 5.788/90 (Araújo, 2008, p. 174). Esta fue la principal 
acción legislativa del FNRU (Santo Amore, 2013). Su aprobación fue resultado directo de la presión del FNRU junto a los congresistas, principalmente en las Comisiones y Relatorías. Inauguró una nueva etapa de la lucha por la reforma urbana, en la medida en que reguló los artículos constitucionales de la política urbana y ofreció la "caja de herramientas" necesaria para que los municipios elaboraran sus Planes Directores (Santo Amore, 2013).

\section{Reforma urbana como movimiento}

La noción de reforma urbana como movimiento está vinculada directamente a la organización de fuerzas sociales en torno al ideario y a los proyectos que fueron conformándose. Leída de esta forma, la reforma urbana puede ser entendida a partir de la acción del Movimiento Nacional de la Reforma Urbana (MNRU). Tales instancias, comprendidas como movimientos sociales, son actores o esferas importantes en la lucha por la reforma urbana, ya sea en el combate o en la interlocución con el Estado, situándose fuera de él; o también en contextos en que se institucionalizan y pasan a actuar inclusive en el interior del Estado, como ocurrió intensamente a partir de la creación del Ministerio de las Ciudades, en un proceso que ya se proyectaba desde la década de 1980.

Durante esta década se concibió el derecho a la ciudad como una pauta en construcción, cuando había una reivindicación por el derecho a la vivienda digna que se incorporaba a una reivindicación más amplia por una reforma urbana y por el derecho a la ciudad. Esta reclamación se concretaría, de acuerdo con las pautas defendidas, a través de la gestión democrática y participativa de las ciudades; del cumplimiento de la función social de la ciudad; de la garantía de justicia social y de condiciones dignas a todos los habitantes de las ciudades; de la subordinación de la propiedad a la función social; y de las sanciones a los propietarios en los casos de no cumplimiento de la función social (Saule Jr. \& Uzzo, 2009). Dicho de otra forma, hay un pasaje desde las luchas localizadas (o sectoriales) a la lucha por el derecho a la ciudad, con la noción de participación, que se vuelve central en el proyecto defendido por la amplia coalición de actores que vendrían a constituir el MNRU.

El MNRU se instituyó como un frente conformado por un grupo heterogéneo de actores, que incluían una serie de organizaciones no gubernamentales, sindicatos, líderes comunitarios, intelectuales y órganos de consultoría técnica a los movimientos urbanos (Santo Amore, 2013). Estos participantes actuaban en temáticas diferentes y complementarias al campo de las cuestiones urbanas. Tal diversidad de actores en torno del MNRU posibilitó la elaboración de proyectos de enmienda populares para la nueva Constitución Federal. De esa manera, el movimiento se articuló en torno a la Asamblea Nacional Constituyente para elaborar la Enmienda Popular de Reforma Urbana. La referida propuesta está marcada "por un carácter 'técnico y especializado', restringiendo así la posibilidad de que el debate hiciese aparecer en la escena pública el juego de intereses políticos presentes en torno de este tema” (Silva, 1991). A pesar de no haber sido aceptada integralmente, representó avances importantes. En el mismo periodo, se consolidó en el MNRU la estrategia de disputa en el campo legislativo. 
Después de la promulgación de la Constitución Federal de 1988, el MNRU se convirtió en el FNRU. Con nuevo formato, pasó a actuar como articulador de una diversidad amplia de actores que defendían la reforma urbana, "de manera menos centralizada que un movimiento y respetando las diferentes formas de organización articuladas en su estructura, a pesar de contar con una coordinación y estrategias claras de acción, pactadas colectivamente" (Serafim, 2013). Las pautas defendidas por el FNRU -cuyos principios ya orientaban la acción del MNRU- se fueron consolidando a lo largo del tiempo en un proceso continuo de definición, de acuerdo con las posibilidades de avance institucional, a partir de tres ejes fundamentales, sujetos a las nociones de justicia social y democracia: derecho a la ciudad; gestión democrática de las ciudades; y función social de la propiedad y de la ciudad, como prevalencia del interés común sobre el derecho individual de propiedad (Saule Jr. \& Uzzo, 2009).

El FNRU pasó a tener como objetivo inmediato la presión -junto al Congreso Nacional- por la reglamentación del Capítulo de la Política Urbana en la Comisión Permanente de Discusión sobre el Desarrollo Urbano e Interior, creada en 1988. Esta comisión se volvió un espacio importante de interlocución para el FNRU en materia de la legislación que rige la política urbana. Ese acompañamiento sistemático da la Comisión era una de las dos estrategias establecidas por el FNRU después de la aprobación de la Constitución. La segunda estrategia era la presión sobre los parlamentarios, participación en debates sobre proyectos de ley, divulgación de informaciones sobre el curso de los proyectos y articulación de acciones con actores más amplios, para inducir a los congresistas a apreciar y aprobar los proyectos referentes a la política urbana (Silva, 2002).

Además, se levantaba la bandera de acción institucional a través de la apertura de espacios de interlocución y cogestión como repertorio de acción fundamental en el campo de la reforma urbana. La construcción de estos espacios fue central en la propuesta de un modelo de gestión democrática de las ciudades, de manera que este es producto de una inserción subsecuente del FnRu en el Ministerio de las Ciudades. Cabe destacar que, desde los años de 1990, el Foro venía acumulando experiencias en la gestión pública. Esto ha ocurrido en diferentes esferas (Ejecutivo y Legislativo) y escalas de poder político (nacional y local), sea a través de la presión, negociación o compromiso de cuadros, de propuestas elaboradas técnicamente y de una red de relaciones amplia e internacionalizada, que generó reconocimiento de la legitimidad del Foro como actor en el campo de la política urbana frente a la sociedad, que concentraba un saber que el propio cuerpo del Estado, a nivel federal, no había acumulado (Serafim, 2013).

\section{Reforma urbana como agenda}

La trayectoria histórica presentada en este texto -en el cual se quiso dar cuenta de la construcción de un ideario, la formulación de proyectos/legislación y la constitución de movimientos en torno de la reforma urbana-, difícilmente puede ser conceptualizada como agenda según el entendimiento adoptado en la Ciencia Política, 
que la considera como una de las etapas del ciclo de las políticas públicas. ${ }^{8}$ A partir de esta premisa, es necesario definir lo que se entiende por agenda y situar conceptualmente lo que se acordó en llamar Agenda de Reforma Urbana.

Puesta como segunda fase de ese ciclo, la agenda setting es el momento en que el problema adquirió relevancia, requiriendo la atención gubernamental. A partir de ahí, se convirtió en una cuestión política, alcanzando estatus de problema público, y así llevando a que las decisiones sobre ese problema resultaran en el diseño de políticas o programas que serían implementados y constituirán la etapa siguiente. Kingdon (2011) define la agenda como "la lista de temas o problemas que en determinados momentos son objetivo de gran atención, tanto de parte de las autoridades gubernamentales como de personas fuera del gobierno, pero estrechamente asociadas a las autoridades". Para hacer frente a su propuesta explicativa, el autor desarrolla un modelo teórico creado con el objetivo de establecer las condiciones necesarias tanto para que un tema entre en la agenda gubernamental y monopolice la atención pública, como para que ascienda en la agenda y provoque cambios en las políticas públicas.

El conjunto que abarca el repertorio de ideas, los proyectos y los movimientos en torno de la reforma urbana, a pesar de aproximarse a los conceptos de Kingdon (2011) - "lista de asuntos o problemas hacia los cuales los actores gubernamentales están dirigiendo seria atención en un momento dado en el tiempo", o una "delimitación del conjunto de cuestiones que los actores focalizarán y discutirán”- no generó una acción gubernamental en tanto conjunto unificado de políticas públicas que constituirían una agenda. Cuestiones relativas a la vivienda, al saneamiento o a la movilidad -que remiten a problemas directamente relacionados con las ciudades y que alimentaron la movilización de actores sociales en la conquista de derechos y de la mejoría de la calidad de vida urbana-, conformaron políticas sectoriales que fueron adquiriendo diferentes matices a lo largo del proceso histórico que caracteriza la lucha por una reforma urbana.

Cabe resaltar que tal trayectoria ocurre en paralelo y vinculada a un acelerado proceso de urbanización "escasamente acompañado de políticas de infraestructura, habitación y planeación, resultando en un acumulado de precariedades, disfuncionalidades y pésimas condiciones de vida y vivienda", incluso con "momentos de fuerte expansión de las políticas para las ciudades" (Marques, 2017). Este autor indica que hubo tres momentos en que las políticas dirigidas a las ciudades se expandieron. El más reciente sucedió ante un vacío del Ejecutivo federal y el incremento del activismo municipal, que amplió el abanico de políticas referentes a las ciudades con la diseminación de acciones de urbanización en asentamientos informales, jornadas autogestionadas, zonas especiales o planeación participativa. Con ello se conformó una nueva agenda urbana diversificada, redistributiva y participativa (Marques, 2017), la cual fue nacionalizada con la creación del Ministerio de las Ciudades. Tal vez aquí esté la clave que ayude a entender el uso inadecuado de la reforma urbana

8 De acuerdo con Frey (2000), el ciclo de políticas públicas estaría compuesto por cinco etapas: percepción y definición de problemas; agenda-setting; elaboración de programas y decisión; implementación y evaluación. 
como agenda. Bajo este prisma, nos encontramos frente a la constitución de una agenda diversificada o un conjunto de agendas de políticas urbanas, en vez de una agenda de la reforma urbana.

\section{Notas finales: límites y contradicciones de la reforma urbana}

$\mathrm{Al}$ afirmar que las ciudades brasileńas viven un impasse y que se cierra un ciclo más de la reforma urbana, Maricato (2011) apunta al momento de evaluación y crítica en que se encuentra una parte significativa del campo político e intelectual. Sus afirmaciones son relevantes para dos reflexiones que abordamos en este texto. En primer lugar, discutimos lo que sería la reforma urbana, a partir de elementos que caracterizan su semántica, presentados en secciones anteriores. Y luego, a partir de las marchas y contramarchas de su proceso histórico, reflexionamos sobre cuáles serían algunos de sus límites y contradicciones. Para ello, rescatamos los principales argumentos expuestos por los trabajos analizados que forman parte del proceso de balance crítico al que nos referimos anteriormente.

Costa (2012) argumenta que la reforma urbana vivió un ocaso, fruto de su despolitización como consecuencia de la institucionalización y de la profesionalización de sus postulados, que convirtieron un ideario como el que dicha reforma representa, a las posibilidades de desarrollo de las fuerzas productivas del capitalismo periférico. Según la autora, hubo una fetichización de la lucha por la tierra y viviendas urbanas, en la medida en que los movimientos sociales se ven cautivados por la ideología jurídica y los avances institucionales y regulatorios. Tal fetichización resulta tanto de un encuadramiento de las potencialidades utópicas en el positivismo jurídico, como del distanciamiento del ideal construido desde los años sesenta (Costa, 2012).

En la misma línea argumentativa, Caldas (2015) afirma que el discurso idealista de una reforma urbana capaz de enfrentar las desigualdades inherentes a la producción capitalista de la ciudad con instrumentos jurídico-urbanísticos, va perdiendo sustento ante la realidad. Esto provoca una degradación de las expectativas, que alcanza una 'utopía mínima', por lo menos por parte de la burocracia estatal y de profesionales conformes con los límites del proyecto de la reforma urbana en la institucionalidad. Hay, por lo tanto, una degradación de las expectativas y ocurre lo que la autora llama "utopía amputada" (Caldas, 2015).

Arantes (2014), a su vez, argumenta que el Programa Democrático-Popular puesto en práctica por el Partido de los Trabajadores en el Ejecutivo federal momento efectivo de institucionalización de la Reforma Urbana- no solo no realizó lo que prometió, sino que produjo lo contrario, una antirreforma urbana, cuya característica visible es la privatización y mercantilización creciente de las ciudades. Incluso siendo la función social de la propiedad una bandera importante desde los inicios de las propuestas vinculadas a la reforma urbana, noción posteriormente asumida por los proyectos y por los movimientos de la reforma urbana, la propiedad privada no fue cuestionada ni combatida, sino solamente regulada y distribuida. Según el autor, la apropiación privada del suelo urbano siguió dictando el modelo de ocupación del mismo, evidenciándose una alianza con el capital para ampliar el mercado e 'incluir' a la clase trabajadora en su 'máquina de (des)hacer ciudades'. 
Sería una alianza de clases por una reforma urbana sin conflictos y con 'mercado para todos'.

Con la mirada puesta sobre el Plan Director, que ocupó un lugar destacado en los análisis, críticas y evaluaciones propias del periodo de balance de la reforma urbana por parte del entorno político e intelectual, Burnett (2009) apunta a una fetichización de la planeación urbana. Explica tal proceso como resultado de la aceptación de formas impuestas por el Estado capitalista en el interior de la lucha popular, traducidas en un predominio del valor del capital por sobre la práctica social institucionalizada de actores que orbitan alrededor de la cuestión urbana. A pesar del empeño en movilizar entidades y líderes populares, los esfuerzos dirigidos a la constitución de una nueva planeación urbana -democrática y popular-a partir de Planes Directores, terminaron por priorizar acciones reformistas en el interior del Estado. Y con ello contribuyeron tanto al desperfilamiento de la reforma urbana, que pasó a asimilar decididamente valores capitalistas, como al debilitamiento de sus bases populares (Burnett, 2009).

Siguiendo la misma línea de análisis sobre el papel que el Plan Director asumió a partir de su exigencia constitucional y su posterior reglamentación vía Estatuto de la Ciudad, Faria (2012) argumenta que la planeación urbana reciente, materializada en el llamado Plan Director Participativo, sería "un nuevo modelo de planeación y gestión de las ciudades", orientado a atender los objetivos de la reforma urbana. Así, produce una metamorfosis de aquel instrumento, que pasa de imposición de los sectores sociales conservadores en la Constitución Federal a elemento importante en la concreción de los principios defendidos, sirviendo a la afirmación de un consenso sobre los elementos constituyentes de la ideología que instituyó un determinado orden político en el cuerpo social de la reforma urbana. El autor destaca las contradicciones entre el ideario consensuado de la planeación urbana politizada y las cuestiones con las cuales se enfrenta la reforma urbana, sobre todo cuando se institucionaliza en el Ejecutivo federal. Para ello, resalta la discordancia entre el predominio del discurso del derecho a la ciudad y la permanencia de la ciudad como negación de derecho, que está fundamentada en los propios límites y lagunas de aquella planeación urbana politizada (Faria, 2012).

Como hemos visto, el recorrido histórico de la reforma urbana da cuenta de un conjunto de avances, principalmente de carácter normativo e institucional, que se materializan en el reconocimiento de derechos de ciudadanos históricamente excluidos, en políticas sectoriales implementadas o en legislaciones e instrumentos urbanísticos y de tierras. Paradójicamente, la realidad objetiva indica que esa historia también se caracteriza por la perversidad de la regresión de las conquistas abstractas de la ley y de las instituciones, representada en los desalojos de población para atender los intereses del mercado especulativo inmobiliario, o en los programas federales de inversión en infraestructura urbana y social que provocaron un boom inmobiliario y que tuvieron un impacto todavía mayor sobre el problema urbano. Si el momento en que la reforma urbana se institucionaliza es aquel en que un ciclo más se cierra, en el que quedan expuestos sus límites y contradicciones y surge un escenario de balance y crítica, ese también puede ser el momento oportuno para resignificarla. 


\section{Referencias bibliográficas}

Arantes, P. F. (2014). Da (anti)reforma urbana brasileira a um novo ciclo de lutas nas cidades. En P. de A. Sampaio Jr. (ed.), Jornadas de junho: a revolta popular em debate (pp. 4146). São Paulo, Brasil: Instituto Caio Prado Jr.

Araújo, M. M. (2008). Politica de desenvolvimento urbano no estatuto da cidade: em que realmente avançamos com o modelo de planejamento regulado pela Lei n. 10.257, de 10 de julho de 2001? En G. M. Costa \& J. G. Mendonça (eds.), Planejamento urbano no Brasil: trajetória, avanços e perspectiva (pp. 170-177). Belo Horizonte, Brasil: C/Arte.

Baldez, M. L. (2003). A luta pela terra urbana. En L. C. Q. Ribeiro \& A. L. Cardoso (eds.), Reforma urbana e gestão democrática: promessas e desafios do Estatuto da Cidade (pp. 7192). Rio de Janeiro, Brasil: Revan/Fase.

Bassul, J. R. (2002). Reforma urbana e Estatuto da Cidade. EURE, 28(84), 133-144. http:// dx.doi.org/10.4067/S0250-71612002008400008

Brasil (1983). Projeto de Lei 775 de 1983. Brasília: Câmara dos Deputados.

Burnett, C. F. L. (2009). Da tragédia urbana à farsa do urbanismo reformista: a fetichização dos Planos Diretores Participativos. Tesis doctoral. Programa de pós-graduaçáo em Políticas Públicas, Universidade Federal do Maranhão, São Luís, Brasil.

Caldas, M. F. (2015). Politica urbana, açâo governamental e a utopia da reforma urbana no Brasil. Tesis doctoral. Universidade Federal de Minas Gerais, Escola de Arquitetura, Belo Horizonte, Brasil.

Cardoso, A. L. \& Ribeiro, L. C. R. (2003). Reforma urbana e gestão democrática: promessas e desafios do Estatuto da Cidade. Rio de Janeiro, Brasil: Fase.

Cities Alliance. (2017). Uma visão geral das leis nacionais urbanas na América Latina e Caribe: estudos de caso do Brasil, Colômbia e Equador. São Paulo, Brasil: Cities Aliance.

Costa, M. de F. T. (2012). Ideologia e utopia no ocaso da reforma urbana no Brasil. Tesis doctoral. Universidade do Estado do Rio de Janeiro, Instituto de Psicologia, Rio de Janeiro, Brasil.

Faria, J. R. V. de (2012). Planos diretores participativos: a razão consensual no discurso da reforma urbana. Tesis doctoral. Universidade Federal do Rio de Janeiro, Instituto de Pesquisa e Planejamento Urbano e Regional, Rio de Janeiro, Brasil.

Fernandes, E. (2002). Apresentação. En L. M. Osório, Estatuto da Cidade e reforma urbana: novas perspectivas para as cidades brasileiras. Porto Alegre, Brasil: Sergio Antonio Fabris.

Fernandes, E. (2008). Reforma urbana e reforma jurídica no Brasil: duas questöes para reflexão. En G. M. Costa \& J. G. Mendonça (eds.), Planejamento urbano no Brasil: trajetória, avanços e perspectiva (pp. 170-177). Belo Horizonte, Brasil: C/Arte.

Frey, K. (2000). Políticas públicas: um debate conceitual e reflexões referentes à prática da análise de políticas públicas no Brasil. Planejamento e Políticas Públicas, (21), 211-259. http://www.ipea.gov.br/ppp/index.php/PPP/article/view/89/158

Kingdon, J. (2011). Agendas, alternatives and public policies. New York: Harper Collins College.

Kowarick, L. (2000). Escritos urbanos. São Paulo, Brasil: Editora 34.

Maricato, E. (2001). Brasil, cidades: alternativas para a crise urbana. Petrópolis, Brasil: Vozes.

Maricato, E. (2011). O impasse da politica urbana no Brasil. Petrópolis, Brasil: Vozes. 
Marques, E. (2017). Cidades, politicas urbanas redistributivas e a crise. Novos Estudos Cebrap, Edição Especial, Volume Dinâmicas da Crise, 41-47, São Paulo, Brasil. http://dx.doi. org/10.25091/S01013300201700040005

Moreira, C. S. (2011). O projeto de nação do governo Joáo Goulart: o plano trienal e as reformas de base (1961-1964). Tesis doctoral. Universidade Federal do Rio Grande do Sul, Programa de Pós-Graduação em Economia, Porto Alegre, Brasil.

onu, Nações Unidas. (2016). Nova Agenda Urbana: Declaração de Quito sobre cidades e assentamentos humanos sustentáveis para todos. Quito, Equador: ONU-Habitat. http:// habitat3.org/wp-content/uploads/NUA-Portuguese-Angola.pdf

Rolnik, R. (2006). A construção de uma política fundiária e de planejamento urbano para o país - avanços e desafios. Cadernos ipea: Políticas Sociais - acompanhamento e análise, 12, 199-210. Brasil: IPEA.

Rolnik, R. (2009). Democracia no fio da navalha: limites e possibilidades para a implementação de uma agenda de Reforma Urbana no Brasil. Revista Brasileira de Estudos Urbanos e Regionais, 11(2), 31. https://doi.org/10.22296/2317-1529.2009v11n2p31

Rolnik, R. (2012). 10 anos do Estatuto da Cidade: das lutas pela Reforma Urbana às cidades da Copa do Mundo. En A. C. T. Ribeiro, L. V. Vaz, \& M. L. P. Silva (eds.), Leituras da cidade. Rio de Janeiro, Brasil: Letra Capital.

Santo Amore, C. (2013). Entre o nó e o fato consumado, o lugar dos pobres na cidade: um estudo sobre as ZEIS e os impasses da Reforma Urbana na atualidade. Tesis doctoral. Universidade de São Paulo, Faculdade de Arquitetura e Urbanismo, São Paulo, Brasil.

Saule Jr. N. \& Uzzo, K. (2011). La trayectoria de la reforma urbana en Brasil. En A. Sugranyes \& C. Mathivet (eds.), Ciudades para tod@s: Por el derecho a la ciudad, propuestas y experiencias (pp. 261-272). Santiago de Chile: Habitat International Coalition. https://bit.ly/36reOOU

Serafim, L. (2013). Participação no Governo Lula: as pautas da reforma urbana no Ministério das Cidades (2003-2010). Tesis doctoral. Universidade Estadual de Campinas, Instituto de Filosofia e Ciências Humanas, Campinas, Brasil.

Serran, J. R. (1976). O IAB e a politica habitacional brasileira: 1954-1975. São Paulo, Brasil: Schema.

Silva, A. A. (1991). Reforma urbana e o direito à cidade. São Paulo, Brasil: Pólis Publicações 1. https://www.polis.org.br/uploads/879/879.pdf

Silva, C. A. (2002). Os fóruns temáticos da sociedade civil: um estudo sobre o Fórum Nacional de Reforma Urbana. En E. Dagnino (ed.), Sociedade civil e espaços públicos no Brasil (pp. 143-185). São Paulo, Brasil: Paz e Terra. 